\title{
VIOLAÇÕES À IMAGEM EMPRESARIAL MARCÁRIA POR MANIPULAÇÃO IMAGÉTICA
}

TRADESMARK'S VIOLATION THROUGH IMAGETIC MANIPULATION

${ }^{1}$ André Luiz Cavalcanti Cabral

${ }^{2}$ Igor de Lucena Mascarenhas

\section{RESUMO}

O presente trabalho objetiva analisar a conduta da mídia e os direitos da personalidade dos empresários que expõem suas marcas em eventos esportivos e culturais. Por intermédio da análise bibliográfica, verifica-se que a mídia não pode manipular a realidade imagética baseada em um interesse estritamente capitalista. Os direitos da personalidade do empresário são óbices para a liberdade absoluta da imprensa. A marca não pode ocultada ou alterada apenas para não ser exibida de forma gratuita. O dever de informar a verdade se sobrepõe aos interesses da mídia, de modo que os prejudicados pela sua atuação ilícita podem pleitear judicialmente a reparação pelos danos causados. A exibição das marcas dos empresários financiadores do evento é um ônus que acompanha o direito de exibição e a liberdade de informar. É uma faculdade promover a cobertura midiática, porém, uma vez optando por fazê-la, deve-se observar a veracidade das informações apresentas.

Palavras-chave: Direito de imagem, Manipulação imagética, Liberdade de mídia

\begin{abstract}
This work aims to analyze the conduct of the media and the personality rights of the companies who expose their brands at sporting and cultural events. Through the literature review, the authors conclude that the media cannot manipulate the imagetic reality based exclusively on financial interests. There is no absolute freedom for the press. The companies personality rights are obstacles to this liberty. The brand cannot be changed or hidden, even if they do not pay for its exhibition. The duty to report the truth overrides the media interests, so the aggrieved can legally claim compensation for the damages done through the actions of the media. The exhibition of the brands that are financing the events is an onus that must be supported by the media, once they decided to cover the event.
\end{abstract}

Keywords: Image right, Imagetic manipulation, Media liberty

\footnotetext{
${ }^{1}$ Doutorando em Direitos Humanos e Desenvolvimento pela Universidade Federal da Paraíba - UFPB, João Pessoa, (Brasil). Professor do Centro Universitário de João Pessoa - UNIPE, Paraíba. E-mail: cabral@ @rc.adv.br ${ }^{2}$ Mestrando em Ciências Jurídicas pela Universidade Federal da Paraíba - UFPB, João Pessoa, (Brasil). Professor Substituto da Universidade Estadual da Paraíba - UFPB, João Pessoa. E-mail: igormascar@gmail.com
} 


\section{INTRODUÇÃO}

A atual sociedade é bombardeada por mensagens curtas e imediatistas como forma de transmitir o maior conteúdo informacional no menor espaço possível. A televisão, jornal e as redes sociais são responsáveis por garantir uma difusão de informação em favor da população e, como forma de financiar suas atividades, utilizam da publicidade de terceiros como meio de receita e, consequentemente, obter eventual lucro.

Os meios de comunicação adquiriram uma importância incomensurável ao se configurarem verdadeiros serviços públicos essenciais para a divulgação da informação. Houve uma época em que dinheiro era sinônimo de tempo. Atualmente, informação é poder e pode ser transacionada como meio de obtenção de lucros. Os recentes escândalos do Wikileaks e as delações premiadas ocorridas na realidade brasileira demonstram que a informação é importante e pode resultar em garantia do direito de locomoção, abertura de processos criminais, criação de conflitos internacionais e a obtenção de vultosas somas de dinheiro.

Na era da informação instantânea, tudo é repassado com o espírito do imediatismo, como forma de alcançar os "furos" jornalísticos, e da eterna novidade ou renovação constantes de conteúdos. Afinal, as informações são rapidamente consumidas e, muitas são descartáveis urgindo sua substituição. As marcas empresariais são facilmente adaptáveis a esse cenário. Sua natureza imagética permite a sua vinculação ao ambiente, seja físico ou virtual, com fácil apreensão informativa pelos destinatários das informações, sejam eles telespectadores, torcedores, internautas, ou qualquer outro expectador visual.

Nesse contexto, diversas marcas têm sido vilipendiadas e agredidas, sobretudo por emissoras televisivas, que manipulam a realidade imagética e desfocam ou invertem as marcas presentes captadas pelas lentes como forma de garantir que nenhuma publicidade "gratuita" seja veiculada. Tal conduta, a princípio, deve ser analisada no sentido de verificar se viola o direito da personalidade do empresário que tem sua imagem modificada e se, eventualmente, causa algum prejuízo de ordem material ou moral.

A análise do direito marcário é essencial para se fixar qual a adequada posição a ser adotada em relação a esse novo modelo de difusão de informação imagética que restringe a publicidade e modifica a realidade. 


\section{A MARCA COMO DIREITO DA PERSONALIDADE DO EMPRESÁRIO}

A pessoa natural ou jurídica é detentora de uma série de direitos inerentes à sua condição, à sua personalidade. Tais direitos são denominados de direitos da personalidade e representam uma série de direitos necessários para o exercício da personalidade, imanentes à própria pessoa.

Diferentemente do que ocorre com a pessoa natural, em que há uma tendência mais imediatista a se reconhecer direitos da personalidade, a pessoa jurídica é uma criação jurídica, uma construção técnica desenvolvida pelo homem como forma de facilitar as transações econômicas. A legislação permitiu a criação de pessoas jurídicas como forma de ampliar as relações sociais, abrindo um maior leque de opções aos sujeitos. Logo, mediante o competente registro, a lei atribui personalidade às pessoas jurídicas, ao passo que às pessoas naturais essa atribuição é inerente à própria condição de ser humano.

Negar direitos da personalidade à pessoa física seria negar a dignidade da pessoa humana, ou seja, violar, de forma frontal, um fundamento da República, consoante dispõe o art. $1^{\mathrm{o}} \mathrm{da} \mathrm{CF} / 88$. A dignidade da pessoa humana é tema formal e materialmente constitucional, representando um direcionamento, um guia para 0toda a conduta de Estado e particulares. ${ }^{1} \mathrm{O}$ homem é fonte e fim para a aplicação da dignidade, de modo que o Estado deve ser um promotor e defensor de direitos. (OLIVEIRA, 2008).

Em relação à pessoa jurídica, sobretudo a que explora atividade econômica, há certa discriminação em relação aos direitos da personalidade. Obviamente que alguns direitos da personalidade não poderão ser detidos por pessoas jurídicas, como vida, liberdade de locomoção e outros de ordem familiar. Porém, a nossa jurisprudência e doutrina têm entendimento pacífico de que a pessoa jurídica possui direitos da personalidade, afinal de contas, é pessoa ${ }^{2}$. Sousa (2011) destaca que os direitos da personalidade, dentre eles a imagem, são bens essenciais para o exercício da personalidade e destaca que o sujeito ativo imediato de tais direitos é a pessoa natural, porém, com menor amplitude, as pessoas jurídicas

\footnotetext{
${ }^{1}$ Desta apresentação é retirada a eficácia horizontal e vertical dos direitos fundamentais, de sorte que eles possuem um raio de ação horizontal, ou seja, para com os iguais, os particulares, bem como possui uma eficácia vertical, destinada ao sujeito que, via de regra, está acima dos particulares, com os quais estabelece uma relação de şubordinação, o Estado.

2 Schreiber (2013) entende que não há dano moral em relação a pessoa jurídica, uma vez que uma notícia injuriosa ou a manipulação da marca não macula a honra da pessoa jurídica e sim possui um efeito patrimonial de difícil quantificação, razão pela qual deveria ser aplicado o parágrafo único do art. 953 do Código Civil.
} 
também deterão alguns direitos da personalidade. Como bem destaca Godinho (2014), a proteção aos direitos da personalidade da pessoa jurídica decorre de expressa previsão no art. 52 do Código Civil e de forma restrita a sua condição artificial, uma vez que a pessoa jurídica não existe de forma concreta e tangível.

A proteção à imagem fundamento constitucional, conforme pode ser extraído do art. $5^{\circ}$ da Magna Carta ao elencar os direitos fundamentais:

Art. $5^{\circ}$ Todos são iguais perante a lei, sem distinção de qualquer natureza, garantindose aos brasileiros e aos estrangeiros residentes no País a inviolabilidade do direito à vida, à liberdade, à igualdade, à segurança e à propriedade, nos termos seguintes:

(...)

V - é assegurado o direito de resposta, proporcional ao agravo, além da indenização por dano material, moral ou à imagem;

$\mathrm{X}$ - são invioláveis a intimidade, a vida privada, a honra e a imagem das pessoas, assegurado o direito a indenização pelo dano material ou moral decorrente de sua violação

Os direitos da personalidade relativos à imagem da pessoa jurídica devem ser analisados com parcimônia e devem ser divididos em duas espécies ${ }^{3}$ : imagem retrato ${ }^{4}$ e imagem atributo. A primeira pode ser caracterizada como a representação físico-material, ao passo que a segunda é a representação mental ou imaterial.

A imagem retrato é considerada a manifestação visível da imagem (GUERRA, 2004). Pode ser caracterizada como a exteriorização da personalidade do indivíduo, além de seu aspecto físico (ARAUJO, 2013). É a captura da fisionomia e das manifestações interiores da pessoa cuja reprodução só poderá ocorrer com a autorização do detentor do direito. Importante destacar que tal autorização poderá ser expressa ou tácita e será dispensável se a imagem do detentor for mero componente de um todo ou se realizada em um espaço público. Significa dizer que dependendo do contexto em que a imagem estiver inserida, a autorização será desnecessária. Como exemplo, podemos citar casos de desastres naturais (enchentes ou terremotos), acidentes e crimes em geral. Em tais situações, o interesse público se sobrepõe ao direito da personalidade do particular. Carvalho (2003) destaca que o animus da captura da imagem é fundamental, de modo que se a captura tiver sido feita em ambiente aberto ao público de forma que a imagem da pessoa somasse ao cenário retratado, nenhum direito à

\footnotetext{
${ }^{3}$ Guimarães (2008) entende que apenas seres racionais possuem imagem atributo, pois os seres irracionais só possuiriam imagem retrato. A partir de tal afirmação, em tese, a pessoa jurídica não teria imagem atributo, uma vez que não é um ser ciente. Todavia, entendemos que pelo fato da imagem moral da pessoa jurídica permear o seio social, há sim uma imagem atributo.

4 Também chamada de imagem espelho pela doutrina portuguesa.
} 
reparação será devido. Por outro lado, se a imagem busca explorar o direito de uma pessoa ou grupo restrito determinado, a indenização seria cabível.

A imagem atributo é o conceito de imagem formado por terceiros em relação ao detentor do direito. É o retrato moral que terceiros detêm sobre a pessoa. Como bem destaca Araújo (2013), a imagem atributo é consequência da vida em coletividade. É o conjunto de características sociais apresentados pelo sujeito mediante o qual é criada uma imagem ou conceito social sobre determinada pessoa. É o entendimento construído pelos homens ao longo do tempo em razão da vida em sociedade. Seria a projeção moral no mundo exterior (DUVAL, 1998).

Neste sentido, podemos extrair que a súmula 227 do $\mathrm{STJ}^{5}$ que dispõe que a pessoa jurídica pode sofrer dano moral, reconhece, de forma clara e cristalina, que a pessoa jurídica possui honra. Ocorre que no caso em comento, essa honra não será subjetiva, pois a pessoa não possui consciência própria para refletir sobre sua honra. Porém, poderá ser aferida a partir do momento em que terceiros refletem acerca da sua honra, ou seja, honra sob a perspectiva objetiva, seu renome ou, ainda, o conceito social acerca da pessoa jurídica.

É possível afirmar que enquanto que para as pessoas físicas os direitos da personalidade possuem natureza jusnaturalista, enquanto que para as pessoas jurídicas possuem natureza positivista, uma vez que o seu reconhecimento decorre da lei. Para os primeiros, tratam-se de direitos inerentes ao homem, dada a própria natureza de essencialidade e formação de um núcleo duro mínimo necessário para o exercício e desenvolvimento da personalidade. Para as pessoas jurídicas, por outro lado, por se tratarem de pessoas criadas por lei, os seus direitos, da mesma forma, derivam da lei.

Justamente, aqui, a marca pode integrar esse patrimônio jurídico imagético da pessoa jurídica. Afinal, a marca é o instituto jurídico da Propriedade Industrial que consiste em todo símbolo (nominal, figurativo, ou híbrido) dotado de distintibilidade, para que se permita a apreensão de qual é a origem de um produto ou serviço, além de orientar consumidores como balizas em suas escolhas no mercado. ${ }^{6}$ Sua funcionalidade é a identificação dos bens aos quais

\footnotetext{
${ }^{5}$ Súmula STJ no 227 : A pessoa jurídica pode sofrer dano moral.

${ }^{6}$ Soares expõe o seguinte conceito: "a marca é o sinal gráfico, figurativo ou de qualquer natureza, isolado ou combinado e que se destina à apresentação do produto e/ou do serviço ao mercado. Por isso deve ser distintiva, especial e inconfundível. Consistindo a marca num sinal qualquer, e empregada esta palavra genericamente, subentende-se que a marca é tudo, dispensando-se assim qualquer forma enumerativa, exemplificativa ou restritiva. Este sinal comumente se apresenta de forma gráfica, tendo por objeto a letra, sílaba, palavra, conjunto de palavras; o número ou conjunto de números; o risco, traço, conjunto de riscos
} 
é aposta. Remete à sua origem, denunciando os responsáveis pela sua oferta, ou seja, esclarece aos consumidores e concorrentes quem está participando do ambiente de mercado, tendo Hobbes afirmado que "a primeira utilização dos nomes, consiste em servirem de marcas ou nota de lembrança" (2001, p. 33).

No Brasil, tem-se o regime de registro junto ao Instituto Nacional de Propriedade Industrial, onde se leva em consideração a novidade, a veracidade, a capacidade distintiva e a licitude para a concessão administrativa da titularidade da marca. As marcas podem ser classificadas segundo critérios diversos, contudo a principal classificação é quanto à sua apresentação, o que evidencia o quanto a sua perspectiva imagética é importante. Tem-se a marca nominativa quando formada de algarismos alfabéticos, figurativa na hipótese de haver apenas figuras ou signos sem adições de palavras ou letras escritas, e, finalmente, a marca mista quando possui tanto elementos figurativos como os nominativos.

Os séculos de utilização da marca nos mercados, a transformaram em reconhecida fonte informativa da origem e qualidade dos bens que se associa distinguindo-os, e que influi na decisão de consumo. Sua natureza jurídica é de bem móvel imaterial, incorpóreo ou intangível ${ }^{7}$, contudo é inegável que passa a compor também um patrimônio moral do empresário sendo sua imagem ou a forma como se apresenta perante o mercado. Dessa forma, fica identificada e reconhecida a existência de uma imagem empresarial marcária, ou seja, dada a posição de destaque que a marca ocupa, no mercado, como farol para o consumo, passouse a constituir elemento do próprio direito de imagem dos agentes econômicos.

A marca pode ser entendida como a reprodução, no mundo, da imagem de uma pessoa jurídica, a sua representação, em especial fisionômica, como meio de inter-relacionamento do elemento distintivo à pessoa. Ou seja, enquanto que a imagem de uma pessoa física pode ser reproduzida por uma fotografia ou gravação, a imagem de uma pessoa jurídica possui correspondência direta com a logomarca, seja ela mista ou apenas figurativa. É o elemento de imagem cognoscível que lhe garante distinção no meio social (GODOY, 2015). Ainda que o

\footnotetext{
ou traços; a sua forma figurativa ou ainda o conjunto das primeiras com esta última." (SOARES;2000, p.16).

7 Negrão afirma que "Do ponto de vista do estabelecimento e identificando sua natureza jurídica, a marca pode ser conceituada como um direito de propriedade incorpóreo, integrante do estabelecimento, que tem como funções distinguir produtos e serviços e, em alguns casos, identificar sua origem e atestar o atendimento desses quanto a certas normas e especificações técnicas.” (NEGRÃO; 2003, p.143).
} 
prédio de determinado empresário possa ser uma representação da sua imagem, a logomarca é o elemento distintivo mais forte na caracterização subjetiva da imagem da pessoa jurídica. ${ }^{8}$

É um direito da personalidade que garante que a imagem não pode ser manipulada ou modificada por terceiros com o fito de obter lucro. A imagem, concretizada, no caso em discussão, pela logomarca, é um direito da personalidade da pessoa jurídica, pois permite o seu contato e reconhecimento imediato pelo aspecto visual, seria o rosto da pessoa jurídica. Representa uma verdadeira projeção da pessoa na sociedade, uma manifestação de sua personalidade em contato com o sentido da visão, o que se pode chamar de aptidão para captação imagética. Como bem destaca Guerra (2004), é a projeção da pessoa ante a sociedade à qual está ligada. Poderíamos configurar a imagem como um traço essencial de garantia de um direito elementar para o contato com o mundo.

Sem a proteção à logomarca, os agentes econômicos poderiam ter sua imagem, que tanto demoraram para criar e construir, ruída pela apropriação por terceiros. Ou seja, um agente econômico externo poderia usufruir de todos os benefícios decorrentes do uso da marca, benefícios estes causados pelo esforço individual do empresário. Não por acaso, a lei 9.279/1996, também chamada de lei de propriedade industrial, dispõe que a marca é sinal distintivo visualmente perceptível e garante a proteção àquela quanto ao uso indevido ou não autorizado de terceiros, o que se entende ser locupletamento com o esforço alheio. Logo, percebe-se que a própria lei trata a marca como elemento visual, reforçando, ainda mais, o seu aspecto imagético e permite a adequação da marca à teoria do direito de imagem retrato.

\section{DA LIBERDADE DOS MEIOS DE COMUNICAÇÃO}

Os meios de comunicação, sobretudo a imprensa ${ }^{9}$, têm a missão de repassar a informação para a população. $\mathrm{O}$ atual momento em que vivemos é formado pela exposição demasiada de informações em que cada veículo de comunicação apresenta uma versão do fato objeto de reprodução, porém o que todos devem perseguir é a verdade. Ou seja, ainda que

\footnotetext{
${ }^{8}$ Neste ponto é necessário destacar que algumas pessoas jurídicas possuem outros elementos distintivos imagéticos clássicos e imediatos como a caracterização de franquias e representações (McDonald`s, Apple e Starbucks) ou de símbolos como "Bonequinho da Michelin" ou o "androide da Android".

${ }_{9}^{9}$ No presente caso iremos trabalhar o conceito de imprensa sob uma perspectiva ampliativa, ou seja, sem restringir ao aspecto meramente jornalístico, e sim todo trabalho informacional produzido por veículo de informação, podendo, deste modo, ser incluída a indústria do entretenimento (programas de celebridades e de cobertura de eventos, por exemplo). Carvalho (2003;p.36) possui entendimento contrário e afirma que "imprensa é atividade jornalística dos jornais, revistas, periódicos, televisão, rádio e internet".
} 
apresentem versões ou visões distintas do mesmo fato, é vedado ao agente comunicador noticiar fato sabidamente falso ou não verdadeiro, sob risco de ser penalizado por tal conduta. Liberdade não pode ser sinônimo de irresponsabilidade. A imprensa tem o dever de veicular notícias, ideias, imagens e informações verdadeiras, ou, ao menos, que subjetivamente não sejam falsas.

A liberdade de informar representa uma liberdade pública, usualmente de natureza oposicional $^{10}$, ou seja, o dever de crítica às irregularidade e erros praticados pelo administrador em desfavor da coletividade. Ocorre que, em muitas oportunidades, os veículos de comunicação são utilizados apenas como meio de entretenimento, uma forma de garantir um lazer para as pessoas em um tempo de descanso. Em tais situações, não há o dever de transmitir informação, no sentido de reportagens e furos jornalísticos investigativos, e sim o meio de comunicação como fonte de prazer para os receptores.

A atual Constituição, após um período da ditadura, buscou garantir uma presunção de liberdade aos agentes, de modo que eventuais excessos libertários sejam penalizados apenas judicialmente. $\mathrm{O}$ art.5 $5^{\circ}$, IX e art. $220, \S 1^{\circ}$ e $2^{\circ}$ são categóricos ao defender a liberdade informacional e o dever de penalização posterior em razão dos excessos cometidos:

Art. 220. A manifestação do pensamento, a criação, a expressão e a informação, sob qualquer forma, processo ou veículo não sofrerão qualquer restrição, observado o disposto nesta Constituição.

$\S 1^{\circ}$ Nenhuma lei conterá dispositivo que possa constituir embaraço à plena liberdade de informação jornalística em qualquer veículo de comunicação social, observado o disposto no art. $5^{\circ}, \mathrm{IV}, \mathrm{V}, \mathrm{X}, \mathrm{XIII}$ e XIV.

$\S 2^{\circ}$ É vedada toda e qualquer censura de natureza política, ideológica e artística.

O conceito de liberdade trazido pela Declaração dos Direitos do Homem e do Cidadão de 1789 traduz bem a extensão desse direito, vejamos:

Art. $4^{\circ}$. A liberdade consiste em poder fazer tudo que não prejudique o próximo. Assim, o exercício dos direitos naturais de cada homem não tem por limites senão aqueles que asseguram aos outros membros da sociedade o gozo dos mesmos direitos. Estes limites apenas podem ser determinados pela lei.

Deste modo, a partir da interpretação do art. $4^{\circ}$ citado, podemos observar que a liberdade não é absoluta, assim como nenhum direito o é. Carvalho (2003) destaca que nenhum direito fundamental é ilimitado, de modo que as antinomias devem ser pacificadas a

\footnotetext{
${ }^{10}$ A imprensa tem o dever de trazer ao tribunal da opinião pública qualquer agente ou autoridade pública mediante a exposição de fatos e informações de interesse público, ante o conceito de coletividade e patrimônio público aplicado ao mundo hodierno.
} 
partir do princípio da ponderação, uma vez que inexiste hierarquia das normas constitucionais. ${ }^{11}$ A limitação de um direito fundamental decorre da necessidade de proteção de outros direitos fundamentais e de bens constitucionalmente reconhecidos. A importância do direito de informar não pode ser negado, porém, assim como nenhum outro direito, não há uma aplicação fria e absoluta do texto constitucional, de modo que o seu exercício está condicionado a determinados limites (ABDO, 2011).

O texto constitucional busca proteger a informação verdadeira, de modo que a divulgação de informação falsa, violando direito da personalidade de terceiro, não goza de nenhum status constitucional (BARROSO,2004). Ocorre que essa não proteção só ocorre nos casos em que houver a atuação deliberada em "plantar" informações falsas no seio social. A informação goza de uma presunção de veracidade, ou seja, deve ser comprovada a atitude deliberada de manipulação ou veiculação da falsidade, de modo que a negligência na investigação ou dolo na difusão não podem ser presumidas.

O Código de Ética dos Jornalistas Brasileiros pontua que a verdade é o norte a ser perseguido:

Art. $2^{\circ}$ - A divulgação de informação, precisa e correta, é dever dos meios de comunicação pública, independente da natureza de sua propriedade.

Art. $3^{\circ}$ - A informação divulgada pelos meios de comunicação pública se pautará pela real ocorrência dos fatos e terá por finalidade o interesse social e coletivo.

$[\ldots]$

Art. $7^{\circ}$ - O compromisso fundamental do jornalista é com a verdade dos fatos, e seu trabalho se pauta pela precisa apuração dos acontecimentos e sua correta divulgação. (sem grifos no original)

De idêntica forma de posiciona a Declaração de Princípios para a Conduta dos Jornalistas, conhecida por Declaração de Bordeaux, ao defender que o respeito pela verdade e pelo direito do público à verdade são deveres do jornalista.

O mesmo vale mesmo que na seara estritamente publicitária, cuja mensagem não pode ser enganosa. A publicidade se ocupará de associar produtos, serviços e organizações a determinada necessidade do mercado consumidor. Neste sentido, pode-se entender que a publicidade busca justamente consolidar nomes, muitas vezes, marcas empresariais como notas de lembrança do mercado consumidor diante de uma certa necessidade de consumo. Por

\footnotetext{
11 A ausência de hierarquia formal entre as normas constitucionais não significa a falta de hierarquia axiológica. Entendemos que temas materialmente constitucionais possuem um maior valor axiológico e constitucional se comparado com temas formalmente constitucionais.
} 
isso, se a publicidade deve ser verdadeira, não se pode permitir sua adulteração sem que o seu responsável concorde ou assuma os riscos.

\section{A MANIPULAÇÃO IMAGÉTICA}

Os meios de comunicação movimentam consideráveis somas de dinheiro com publicidade. Apenas como forma exemplificativa, podemos citar o lucro obtido pelas maiores redes de televisão aberta no país que demonstram a pujança financeira do setor. A Rede Globo obteve $\mathrm{R} \$ 2,36$ bilhões em lucro líquido no ano de 2014 (TELECO, 2015) e a Rede Record obteve uma receita bruta de R $\$ 2,25$ bilhões em 2013 (CASTRO, 2015).

Esse montante, se considerarmos que são apenas dois grupos econômicos, demonstra que, apesar do faturamento elevado, há um capitalismo feroz e insaciável em busca de maiores lucros.

Abel Balbino Guimarães (2008; p. 46) pontua que a inovação tecnológica favorece as lesões ao direito de imagem. “A imagem objetiva pode sofrer alteração material física da pessoa, mediante conhecidos e sofisticados truques de falsas montagens, acréscimos, cortes, justaposições, invenções, supressões e outras formas" como forma de favorecer os interesses do violador de direito. As imagens abaixo demonstram a conduta ilícita praticada por algumas empresas de comunicação, vejamos:

Figura 1 - Imagem espelhada

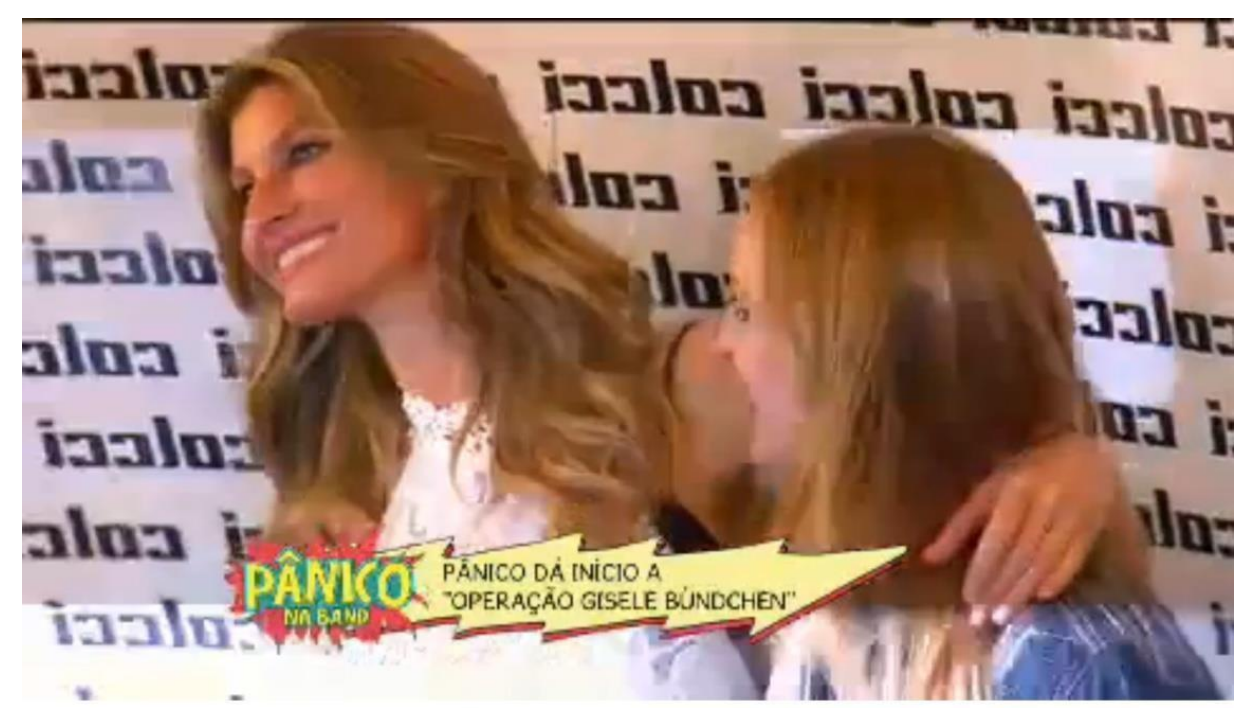

Fonte: Sítio oficial da Bandeirantes 
Figura 2 - Imagem Espelhada

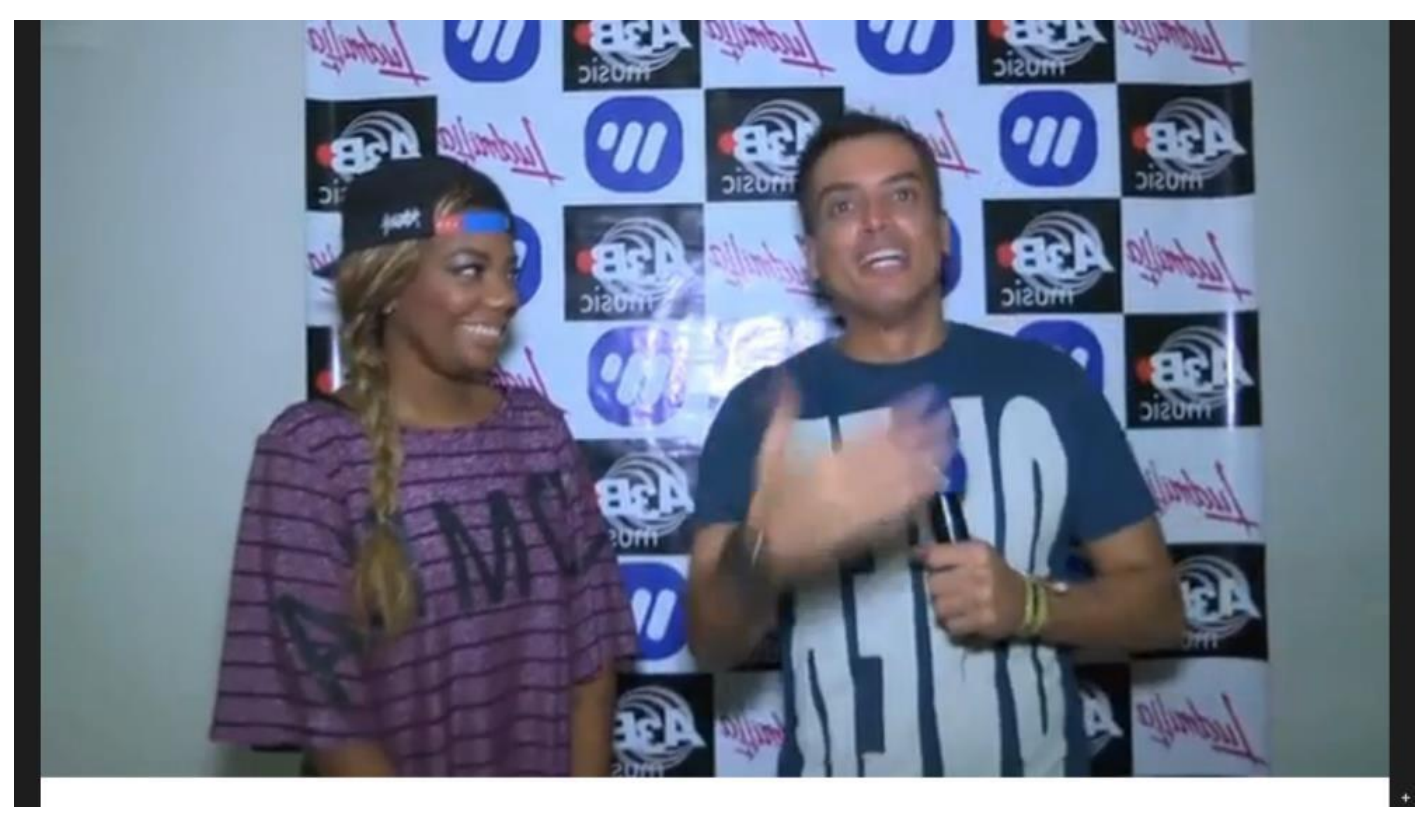

Fonte: Sítio oficial da RedeTV

Figura 3 - Imagem Espelhada

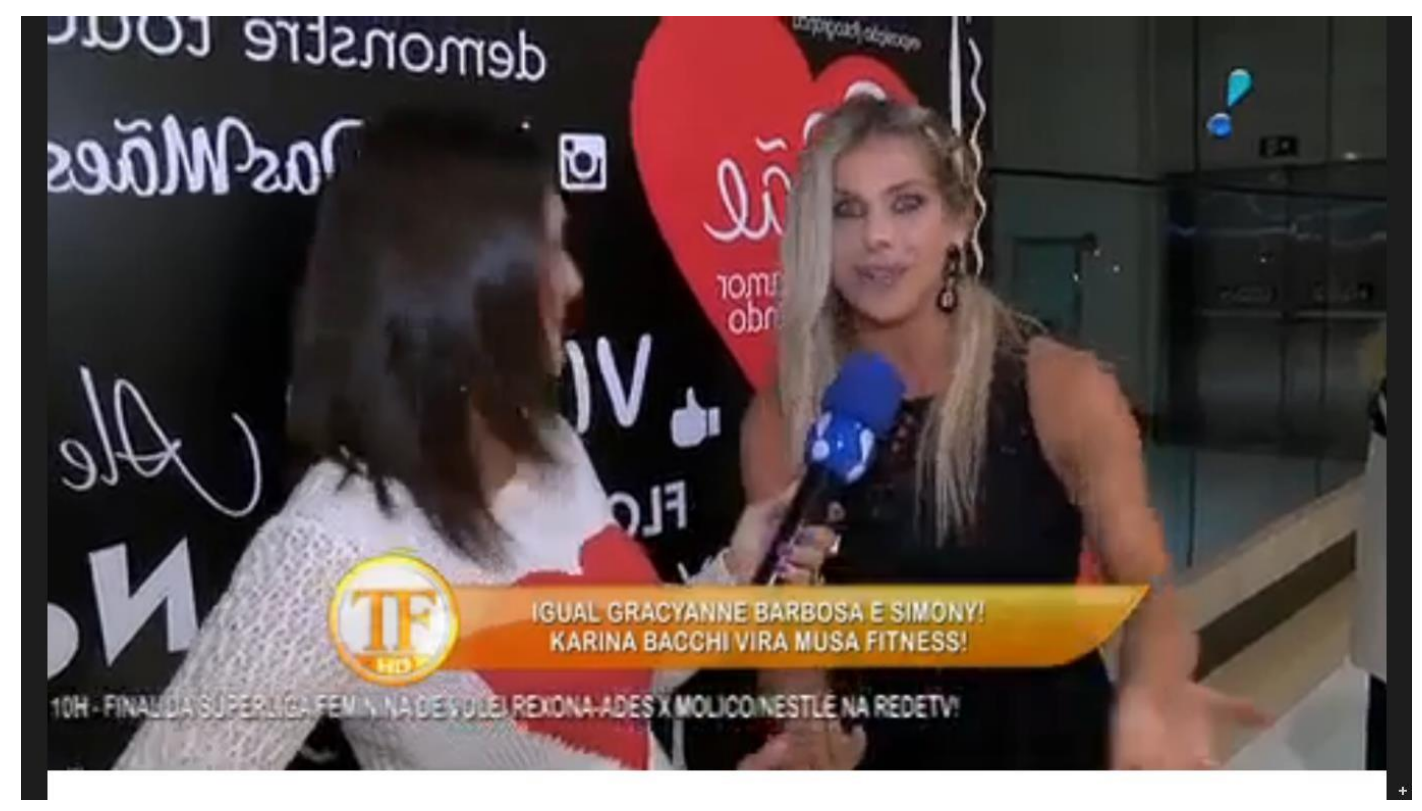

Fonte: Sítio oficial da RedeTV 
Figura 4 - Imagem Embaçada

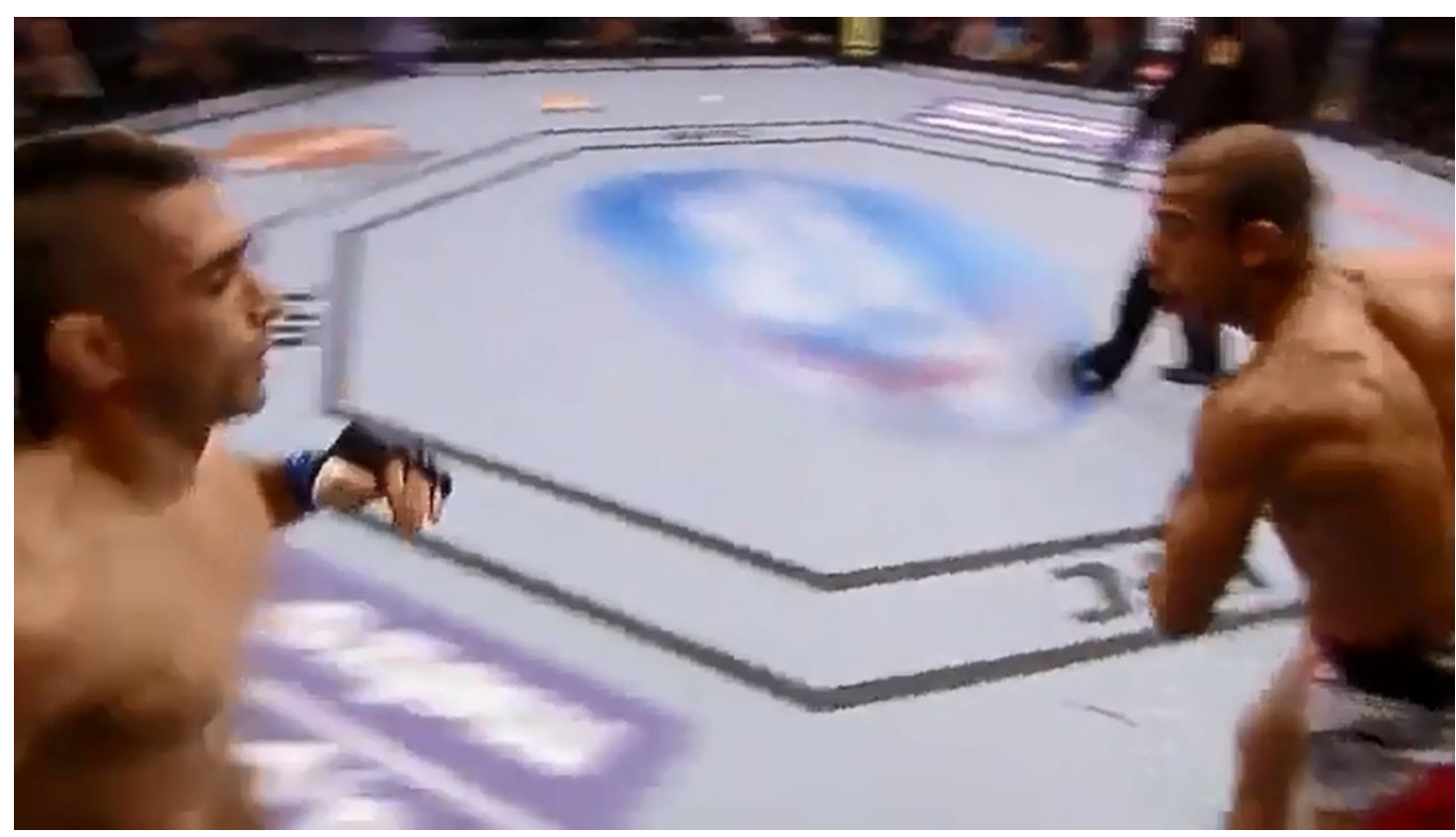

Fonte: Sítio oficial da Rede Globo

Os quatro exemplos apresentados indicam que houve manipulação da realidade imagética. Enquanto que nos três primeiros exemplos, temos a técnica de "imagem espelhada", onde podemos observar que as emissoras optaram por inverter a imagem, dificultando ou impedindo o reconhecimento das empresas apoiadoras dos eventos culturais, esportivos ou de qualquer outra natureza. Por sua vez, no quarto exemplo temos o embaçamento das logomarcas, onde a imagem é desfocada ao ponto de ficar muitas fezes irreconhecível, pois só restam as cores originais ao fim do processo, trata-se da técnica de "imagem embaçada".

Entendemos que as duas condutas são ilícitas e condenáveis. Na técnica de "imagem embaçada", por meio de seu embaçamento no meio de comunicação a marca fica com seu reconhecimento dificultado ou impedido, o que significa grave prejuízo econômico pois anula os efeitos da ação de marketing do patrocínio. No efeito espelho, há a verdadeira violação da imagem marcária ao modificar a logomarca. O impedimento de reconhecimento casado pela técnica de "imagem embaçada" é grave, pois frusta investimentos, o que se aproximiria da hipótese de um dano material. Porém, na técnica de "imagem espelhada" ocorre a "criação" de uma nova marca para um empresário que já possui a sua constituída e firme no mercado, uma manipulação, portanto, não autorizada e que pode ser entendida como causadora de 
danos morais, além dos danos materiais já que, também, frusta investimentos com o patrocínio realizado.

Diferentemente do que foi defendido por Guerra $(2004)^{12}$, entendemos que a simples manipulação da logomarca, no sentido de violação à imagem retrato, é passível de indenização correspondente à lesão sem que haja a necessidade de comprovação do dano moral. Em relação ao dano material, este deverá ser comprovado, porém entendemos que também é plenamente aplicável e plausível a sua pretensão (GUIMARÃES, 2008).

O embaçamento deve ser garantido apenas para preservar um interesse maior, observado o princípio da ponderação. Curiosamente, podemos observar que quando essa ferramenta deve ser utilizada, é menosprezada, como nos programas policiais em que a imagem de um cadáver é exibida sem o menor pudor, ao passo que quando deveria ser dispensável, como nas publicidades, é utilizada. A imprensa marrom, também chamada de sensacionalista, com o objetivo de angariar ibope, e mais anunciantes, explora as mazelas da vida cotidiana à sua exaustão. Todos os estados brasileiros possuem, ao menos, um programa policial em uma emissora de televisao aberta e tais "jornais", utilizando de um populismo e violação à dignidade da pessoa humana, exibem sem cortes, manipulações ou restrições às imagens de vítimas e crimes bárbaros, beirando a banalização da vida (GUIMARÃES, 2008). Ou seja, pode-se observar que os instrumentos tecnológicos são subutilizados nas situações necessárias e excessivamente aplicados em momentos inoportunos, porém em todos os casos possuem um único objetivo: aumento do lucro.

Em todos as figuras apresentadas vemos um ponto em comum: ocultação de marcas que apoiam eventos esportivos ou culturais em razão de interesses patrimoniais. Ora, essa manipulação da realidade representa um desestímulo aos empresários de patrocinarem os eventos, pois não haverá garantia de contrapartida ao valor despendido. A partir do momento em que o empresário investe em publicidade, ele espera que sua marca seja vista e reconhecida amplamente. Ocorre que com a inversão ou embaçamento, esse retorno não ocorrerá, ou, ao menos, será dificultado, sobretudo para marcas não estabelecidas para o grande público. Não haverá informação livre e sim uma deformacao factual objetivando a manipulacao da opinião pública (TESTA JÚNIOR, 2011).

\footnotetext{
${ }^{12} \mathrm{O}$ autor destaca que apenas a imagem atributo prescinde de comprovação de dano.
} 
Logo, podemos observar que a atitude dos veículos de comunicação em manipular as imagens pode representar um decréscimo da atividade financiadora de eventos e ainda em um possível ajuizamento de ações indenizatórias de ordem moral e material. Ou seja, uma questao meramente financeira, a não exibição de publicidade "gratuita", poderá ter reflexos danosos na promoção da cultura / esporte, além de assoberbar, ainda mais, o Judiciário com demandas relativamente simples.

Afinal, há uma função social do patrocínio que é uma grande ferramento do chamado marketing social. Ao passo que as manipulações imagéticas destorcem a realidade para informar seletivamente, ou mesmo, deliberadamente omitir informações, elas depreciam o retorno de invertimento das cotas de patrocínios dos eventos esportivos e culturais em geral. Dessa forma, as práticas aqui examinadas, quais sejam a técnica de "imagem embaçada" e a técnica de "imagem espelhada" atentam contra não só os direitos de imagem da pessoa jurídica, mas também, enfraquecem a estrutura economico-social das atividades esportivas e culturais e, assim sendo, desinteressa sua proliferação e fomento no seio social.

\section{CONCLUSÃO}

A publicidade, na economia capitalista contemporânea, é essencial para os empresários por se tratar de meio de comunicação social com amplo alcance e permitir a difusão das suas marcas para o público consumidor. Com tal objetivo, são criadas e registradas marcas para assegurar os investimentos publicitários e garantir uma maior identificação entre a oferta e a demanda, principalmente quanto à origem e aos aspectos qualitativos do produto ou serviço anunciado.

Busca-se, assim, uma maior abrangência das mensagens e valores atrelados às marcas, por isso os empresários promovem e patrocinam eventos esportivos e culturais, uma vez que estes possuem ampla cobertura da mídia e despertam o interesse popular. As marcas são expostas em tais eventos e, mediante a difusão do evento na mídia, de forma reflexa, são apresentadas ao público. Trata-se de uma forma de publicidade encoberta em que a marca não é diretamente apresentada ao público e, sim, indiretamente, por intermédio do evento.

Ocorre que a mídia obtém suas receitas a partir da publicidade paga por empresários interessados em terem suas marcas exibidas. Deste modo, a publicidade realizada sem a contrapartida geraria, a princípio, uma perda de capital das empresas de mídia, pois haveria 
um potencial desinteresse dos anunciantes em financiarem a publicidade regular. Com o objetivo de promover a contratação de seus canais diretos de publicidade, a mídia tanto televisiva quanto à virtual (internet) promovem a manipulação da realidade imagética das marcas. Trata-se de prática que configura violação aos direitos da personalidade do empresário e descumprimento do dever de retratar a verdade, além de desestimular o suporte ou patrocínio de eventos em geral, pois elimina a publicidade indireta.

A marca é um direito da personalidade do empresário que, mediante o patrocínio de eventos, busca a sua exposição e aumento de seus lucros. Quando a mídia altera a realidade imagética e impede que a publicidade de eventos alcance sua plena função: permitir a identificação e aumentar os lucros do empresário, mas também, o que é mais grave, distorce a realidade pautada no mesmo fim egoístico de aumentar os lucros do setor publicitário.

Ademais, há um claro conflito entre a liberdade de mídia e o direito à imagem. Como não há direito absoluto, considerando o princípio da ponderação, deve-se analisar no caso concreto qual dos dois direitos deve se sobrepor. A justificativa para não se respeitar o direito à imagem possui cunho nitidamente capitalista, ou seja, impedir que as marcas sejam identificadas para não privilegiar uma pretensa publicidade "gratuita".

Todavia, a gratuidade dessa publicidade é uma falácia, pois o patrocínio de evento representa o pagamento em favor do responsável ela sua organização para que a marca seja apresentada de forma favorável. Ou seja, o pagamento é feito, só que para pessoa diversa daquele que, indiretamente veicula a publicidade. Contudo, são os eventos de toda natureza fonte de notícias que atraem a atenção para os conteúdos jornalísticos gerais ou especializados dos canais clássicos de mídia, e, portanto, ao gerarem audiência ou expectadores para estes os fortalecem para a venda dos seus espaços diretos de publicidade.

A mídia tem o dever de veicular a publicidade apresentada no evento, uma vez que aquela representa a realidade retratada. A exibição / cobertura dos eventos acarreta consigo o ônus de exibir as marcas ali apresentadas, uma vez que sem elas, talvez o evento não tivesse capacidade financeira para ser realizado, o que denuncia uma função social do próprio patrocínio.

A manipulação imagética representa uma violação do dever de veracidade informativa e do direito da personalidade do empresário, o que permitirá que os prejudicados que não tiveram suas marcas exibidas demandem civilmente a mídia por todo o dano causado 
decorrente da técnica de "imagem embaçada" ou de "imagem espelhada". Em uma ou outra situação, haverá a violação da imagem atributo e/ou imagem retrato, sob o aspecto moral, além do aspecto material decorrente de todo o investimento realizado e que não obteve o retorno esperado.

A mídia deve aprender que em paralelo ao direito de informar, há o dever de informar a verdade, sob pena de representar um desserviço social. A liberdade de informar não pode ser utilizada como uma liberdade absoluta e violadora da função social da mídia. $\mathrm{O}$ atual contexto do mercado demanda uma evolução das relações sociais e, consequentemente, uma nova forma de encarar métodos de publicidade sem, contudo, prejudicar terceiros e promover o abuso de direito.

\section{REFERÊNCIAS}

ABDO, Helena. Mídia e processo. São Paulo: Saraiva, 2011.

ARAUJO, Luiz Alberto David. A proteção constitucional da própria imagem. 2 ed. São Paulo: Verbatim, 2013.

BARROSO, Luis Roberto. Colisão entre liberdade de expressão e direitos da personalidade. Critérios de ponderação. Interpretação constitucionalmente adequada do Código Civil e da Lei de Imprensa. Revista de direito administrativo, v. 235, p. 1-36, 2004.

CARVALHO, L.G. Grandinetti Castanho de. Liberdade de informação e o direito difuso à informação verdadeira. Rio de Janeiro: Renovar, 2003.

\section{CASTRO, Daniel. Lucro da Globo é maior que todo o faturamento anual da Record.}

Disponível em http://noticiasdatv.uol.com.br/noticia/mercado/lucro-da-globo-e-maior-quetodo-o-faturamento-anual-da-record-2815. Acesso em 12 de jul. de 2015.

DUVAL, Hermano. Direito à imagem. São Paulo: Saraiva, 1988

FELTRIN, Ricardo. Receita cresce, mas cai lucro do Grupo Globo. Disponível em http://celebridades.uol.com.br/ooops/ultimas-noticias/2015/03/26/receita-cresce-mas-cailucro-do-grupo-globo.htm. Acesso em 12 de jul. de 2015. 
GODINHO, Adriano Marteleto. Direito ao próprio corpo: direitos da personalidade e os atos de limitação voluntária. Curitiba: Juruá, 2014.

GODOY, Claudio Luiz Bueno de. A liberdade de Imprensa e os Direitos da Personalidade. 3 Ed. São Paulo: Atlas, 2015.

GUERRA, Sidney Cesar Silva. A liberdade de imprensa e o direito à imagem. São Paulo: Renovar, 2004

GUIMARÃES, Abel Balbino. Responsabilidade do Estado por dano à imagem. Cuiabá: Janina, 2008.

HOBBES, Thomas. Leviatã ou Matéria, Forma e Poder de um Estado Eclesiástico e Civil. Tradução Pietro Nassetti. São Paulo: Martin Claret, 2001.

NEGRÃO, Ricardo. Manual de Direito Comercial e de Empresa. vol.1. $3^{\text {a }}$ ed. reform. De Acordo com o Novo Código Civil (Lei n 10.406, de 10-1-2002). São Paulo: Saraiva, 2003.

OLIVEIRA, Rafael Thomaz. Decisao judicial e o conceito de principio: A hermenêutica e a (in)determinação do Direito. Porto Alegre: Livraria do Advogado, 2008.

REDETV! MC Ludmilla fala sobre lipo: 'Agora eu quero exibir a barriga'. Disponível em http://www.redetv.uol.com.br/tvfama/videos/todos-os-videos/mc-ludmilla-fala-sobre-lipoagora-eu-quero-exibir-a-barriga. Acesso em 26 de abril de 2015.

REDETV!. Karina Bacchi quer apagar seu passado das redes sociais. Disponível em http://www.redetv.uol.com.br/tvfama/videos/celebridades/karina-bacchi-quer-apagar-seupassado-das-redes-sociais. Acesso em 26 de abril de 2015.

SCHREIBER, Anderson. Direito Civil e Constituição. São Paulo: Atlas, 2013.

SOARES, José Carlos Tinoco. Marcas vs. Nome Comercial: Conflitos. São Paulo: Jurídica Brasileira, 2000.

SOUSA, Rabindranath V. A. Capelo de. O direito geral de personalidade. Coimbra: Coimbra Editora.2011.

TELECO. Redes de TV. Disponível em http://www.teleco.com.br/TV_redes.asp. Acesso em 12 de jul. de 2015.

TELEVISÃO BANDEIRANTES. Operação Gisele Bündchen faz modelo entrar no Dubsmash. 
http://entretenimento.band.uol.com.br/paniconaband/videos/15446538/operacao-giselebundchen-faz-modelo-entrar-no-dubsmash.html. Acesso em 26 de abril de 2015.

TESTA JÚNIOR, Washington Luiz. Informação, direito e verdade: regulação constitucional da imprensa. Curitiba: Juruá, 2011.

THE ULTIMATE FIGHTER BRASIL 4. Disponível em http://globoesporte.globo.com/lutas/tuf-brasil/. Acesso em 12 de jul. de 2015. 